\title{
Prognosis of Diabetes Mellitus in a Geographically Defined Population
}

\author{
G. Panzram and R. Zabel-Langhennig \\ Outpatient Department of Internal Medicine, Medical Academy, Erfurt, German Democratic Republic
}

\begin{abstract}
Summary. The centralised registration and care of all diabetics in a geographically defined population has provided an epidemiological basis for a longitudinal investigation of the prognosis of this disease. Records of all newly diagnosed diabetics who had been registered in the Erfurt district (population 1.25 million) in 1966 were studied in relation to the time period 1966-1976. Of the known 2,560 diabetics (910 men, 1,650 women; $93.7 \%>40$ years of age), 1,054 had died during the 10-year follow-up period. Cardiovascular causes accounted for the majority of deaths $(63 \%)$. In almost all age classes proportionally more men than women had died at follow-up; there was a significant difference in the 60-69 year group (men $61.6 \%$, women $46.2 \%$ ). In comparison with the general population, excess mortality ranged from 2.1 to 1.0 , decreasing with age at onset without significant differences between men and women. Excess mortality was present in most age classes and was evident within the first year after diagnosis. Current life-table analysis confirmed the shortened life expectancy of the diabetics. The lower lifeexpectancy of noninsulindependent diabetics may not be due to hyperglycaemia alone but probably also involves a variety of atherogenic risk factors.
\end{abstract}

Key words: Arteriosclerosis, excess mortality, life expectancy, life-table method, median survival time, mortality, non-insulin-dependent diabetes mellitus, prognosis of diabetes mellitus

Except for two prospective population studies $[1,2]$, most investigations of the prognosis of diabetes have been affected by unknown selection factors. This limitation applies not only to the analysis of life insurance data [3-5] and death certificates [6, 7], but also to numerous outpatient and inpatient studies [7-14].

The dispensary system of the German Democratic Republic offers an opportunity of gaining unbiassed prognostic information from a complete diabetic population. In this system health care centres are responsible for central registration, medical treatment and social welfare of all diabetics. Thus, in the district of Erfurt (1.25 million inhabitants) a diabetes register has existed since 1956. Documentation of the course of the disease is available from the 14 Advisory Boards caring for diabetics in the area. Earlier analyses of long-term observations of this closed population have already produced epidemiological information on the natural history of the disease and on the influence of preventive and therapeutic measures [15-17]. The aim of our present study was to gain representative information on mortality ratios, life expectancy and causes of death in newly diagnosed diabetics, comparing their experience with that of the whole population.

\section{Patients and Methods}

The patient population included all 2,560 diabetics newly diagnosed in the Erfurt district in 1966. The central registration and subsequent treatment of all these patients in the 14 regional diabetes care centres of the district allowed a selection-free follow-up. Diabetes was defined according to the 1965 WHO recommendations: fasting true blood sugar level over $130 \mathrm{mg} / \mathrm{dl}$ and/or $2-\mathrm{h}$ blood glucose value (capillary) of $140 \mathrm{mg} / \mathrm{dl}$ or more after $50 \mathrm{~g}$ oral glucose load [18]. The time-point at which diabetes was diagnosed was used as the date of onset.

In 1966, the prevalence of diabetes in the district of Erfurt was $1.38 \%$ (17,234 diabetics $/ 1,249,540$ inhabitants). The 2,560 investigated diabetics represent an incidence rate of $0.20 \%$. Table 1 shows the characteristics of this cohort of diabetics. The mean age of the male diabetics was 58.2 years and that of female patients 61.2 years. The sex and age distribution as well as the high per- 
Table 1. Distribution of sex, age, weight and treatment of 2560 diabetics newly diagnosed in the district of Erfurt in 1966

\begin{tabular}{|c|c|c|c|}
\hline \multicolumn{4}{|c|}{ Number of cases } \\
\hline Total & Females & Males & \\
\hline 2,560 & 1,650 & 910 & \\
\hline \multicolumn{4}{|c|}{ Age at diagnosis (years) } \\
\hline$<20$ & $20-39$ & $40-59$ & $60+$ \\
\hline $1.0 \%$ & $5.3 \%$ & $37.0 \%$ & $56.7 \%$ \\
\hline \multicolumn{4}{|c|}{ Weight at diagnosis ${ }^{a}$} \\
\hline$\leqslant+10 \%$ & $+11-30 \%$ & $+31-50 \%$ & $+50+\%$ \\
\hline $10.0 \%$ & $28.6 \%$ & $29.2 \%$ & $32.1 \%$ \\
\hline \multicolumn{4}{|c|}{ Treatment $^{b}$} \\
\hline Diet & Oral agents & Insulin & \\
\hline $34.7 \%$ & $51.3 \%$ & $14.0 \%$ & \\
\hline
\end{tabular}

a Weight classification based on the Metropolitan Life Insurance Company Life Tables criteria

b Patients with changes in therapy have been classified according to the treatment initiated for the longest period of time

centage of overweight suggest that our patients were predominantly diabetics of Type 2 .

The analyses of prognosis are based on records of the 10 years following onset, that is from 1966 to 1976 . Time and cause of death were reliably documented. Information on causes of death was obtained from death certificates; autopsy results were available for $21 \%$ of deaths. The evaluation of causes of death was based on the WHO classification.

Due to the low mobility of the general population, only 179 patients $(7 \%)$ were lost to follow-up; the main reason was change of residence, and in some cases remission of diabetes due to drastic loss of weight.

The following criteria were used to evaluate mortality and prognosis:

- Mortality after 10 years.

- Median survival time, for age classes with a mortality rate over $50 \%$.

- Cumulative survival rate, as compared with the general population using the cohort life-table method [19].

- Excess mortality after the first and tenth years, as compared with the general population.

- Life expectancy according to the current life-table method [20].

G-Test according to Woolf [21a] was used to evaluate the differences in the rates of mortality and frequencies of causes of death. Statistical analysis of the cumulative rates of survival was performed by comparing two coefficients of regression, using Student's t-test [21b]. The three-dimensional contingency table [22] was employed for statistical analysis of excess mortalities.

\section{Results}

\section{Mortality}

Of the 2,381 diabetics remaining after exclusion of those lost to follow-up, $1,054(44.3 \%)$ had died by the time of the 10-year follow-up. Death rate was related to age at onset (Fig. 1). Ten-year mortality rates in the age groups $40-49,50-59,60-69$ and $70-79$ years were $11.7 \%, 26.3 \%, 51.4 \%$ and $82.1 \%$,

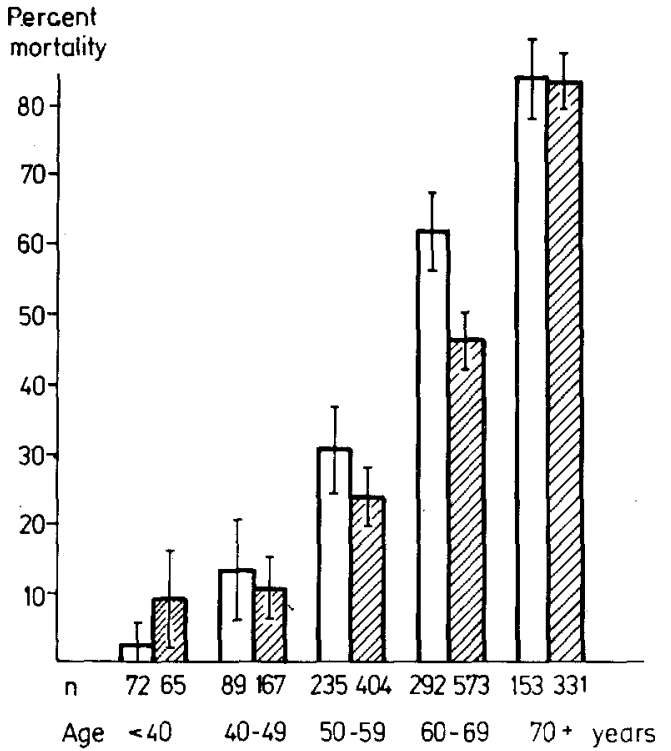

Fig. 1. Mortality rates at 10 -year follow-up for all diabetics newly detected in the Erfurt district during 1966, classified by sex and age at time of diagnosis. Open bars $=$ males, hatched bars $=$ females

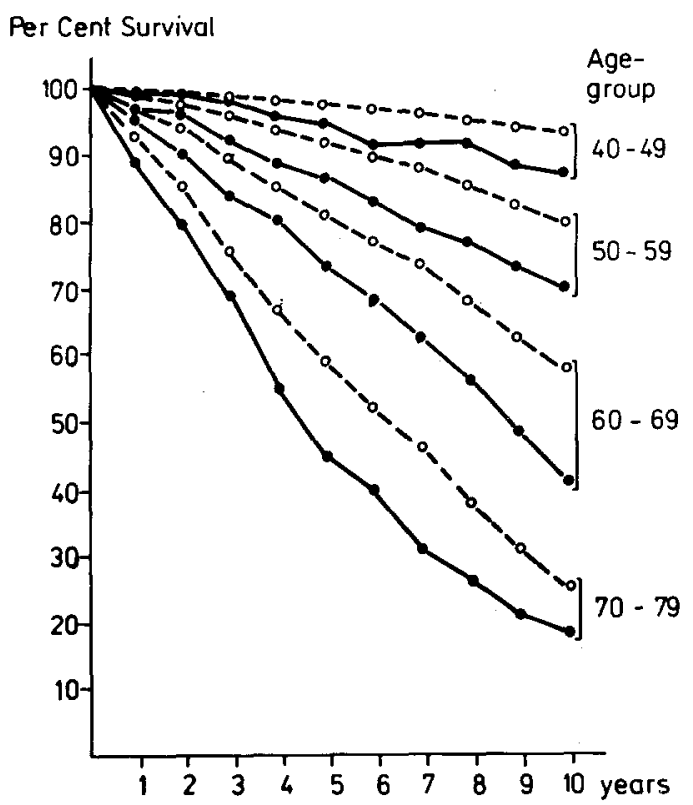

Fig. 2. Cumulative survival rates at 10 -year follow-up for male diabetics - - ) as related to age at time of diagnosis (cohort life table method) [19]. The comparison curves (O-O) represent the corresponding age groups of males in the general population. The expected mortality values were estimated on the basis of the annually published death rates for the population in the Erfurt district by compiling a life table for hypothetical population cohorts, in accordance with diabetics with reference to age and sex. The differences between diabetics and general population were statistically significant $(p<0.01)$ in all age groups except for the group aged $70-79$ years 
respectively. Mortality rates were generally higher in men, the difference being statistically significant for the age group $60-69$ years $(p<0.01)$. Median survival time could only be calculated for males over 60 years and females over 65 years. The median survival time confirmed the relationships of mortality to age and sex as shown in Fig. 1.

\section{Cumulative Survival Rate}

The cohort life-table method allowed further analyses of mortality throughout the observation period, including data from drop-outs for the period during

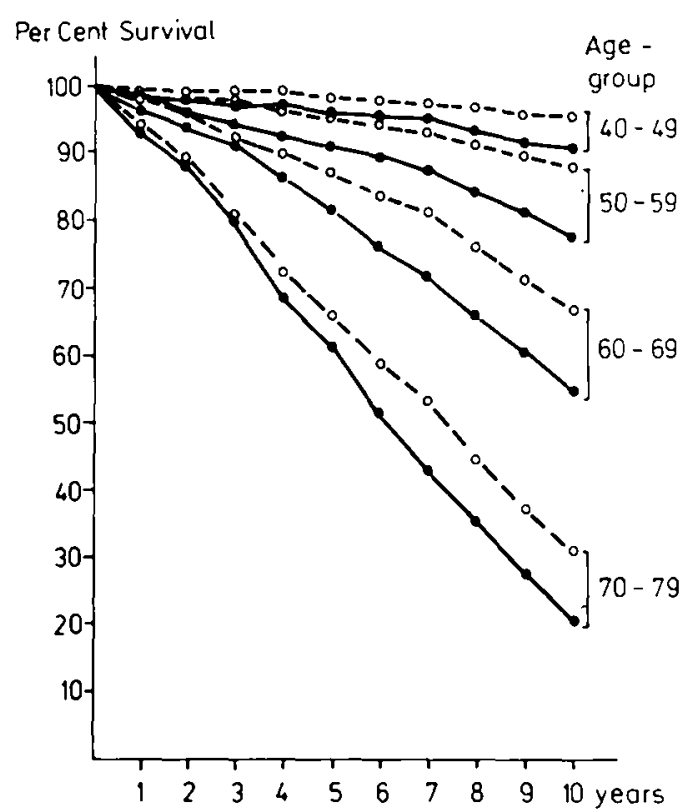

Fig. 3. Cumulative survival rates at 10 -year follow-up for female diabetics as related to age at time of diagnosis (for details see Fig. 2). The differences were statistically significant $(p<0.01)$ between diabetics and the general population in all age groups which their records were available. Comparison of the survival curves for male (Fig. 2) and female diabetics (Fig. 3) with the survival curves of the corresponding sex and age groups from the general population of the Erfurt district showed a significantly higher mortality for diabetics of both sexes and all age groups, with the exception of men aged 70-79 years.

\section{Excess Mortality}

Comparison of the 10 -year mortality rate of the diabetic group with the corresponding value for the total population of the Erfurt district results in an excess mortality ratio for diabetics ranging from 2.17 to 0.96 , depending on age (Table 2). Excess mortality of the diabetics was greatest in the younger age groups. Table 2 shows that excess mortality occurred even during the first year, the mortality rate in some age groups being as much as two to three times that in the total population. There were no significant sex differences in excess mortality.

\section{Life Expectancy}

Using the first year mortality rate as a basis, a current life-table [20] was calculated to predict further life expectancy for the diabetic group. Figure 4 compares the life expectancy figures calculated for 5-year age classifications of the diabetic patients aged above 40 years with corresponding life expectancy figures of the total population in the German Democratic Republic in 1966/67 [23]. Due to the small absolute number of deaths in diabetics, separate calculations for males and females were not feasible. However, the less favourable prognosis of the diabetics is apparent.

Table 2. Excess mortality 1 and 10 years after the diagnosis of diabetes in the age groups from 40 to 79 years

\begin{tabular}{|c|c|c|c|c|c|c|}
\hline \multirow{3}{*}{$\begin{array}{l}\text { Age } \\
\text { at } \\
\text { diagnosis } \\
\text { (years) }\end{array}$} & \multicolumn{2}{|c|}{ Number of diabetics at diagnosis } & \multicolumn{4}{|c|}{ Excess mortality } \\
\hline & \multirow[b]{2}{*}{ Males } & \multirow[b]{2}{*}{ Females } & \multicolumn{2}{|c|}{$\begin{array}{l}1 \text { year } \\
\text { after diagnosis }\end{array}$} & \multicolumn{2}{|c|}{$\begin{array}{l}10 \text { years } \\
\text { after diagnosis }\end{array}$} \\
\hline & & & $\overline{\text { Males }}$ & Females & Males & Females \\
\hline $40-44$ & 44 & 81 & $-{ }^{a}$ & $11.16^{\mathrm{a}}$ & 1.80 & 2.17 \\
\hline $45-49$ & 51 & 99 & $4.17^{\mathrm{a}}$ & $2.89^{\mathrm{a}}$ & 1.82 & 1.99 \\
\hline $50-54$ & 89 & 173 & $2.57^{a}$ & 1.08 & 1.26 & 1.82 \\
\hline $55-59$ & 157 & 255 & 2.24 & 2.94 & 1.56 & 1.88 \\
\hline $60-64$ & 182 & 278 & 1.35 & 1.90 & 1.49 & 1.48 \\
\hline $65-69$ & 137 & 322 & 1.60 & 1.77 & 1.37 & 1.33 \\
\hline $70-74$ & 93 & 220 & $1.37^{\mathrm{a}}$ & 1.34 & 1.21 & 1.26 \\
\hline $75-79$ & 50 & 112 & $1.66^{\mathrm{a}}$ & 0.95 & 0.96 & 1.04 \\
\hline
\end{tabular}

a Values based on less than 100 patients 


\section{Causes of Deaths}

The majority of deaths $(63.4 \%)$ was due to cardiovascular disease, mainly manifestations of arteriosclerosis. The higher frequency of cardiovascular deaths in women may be due to their higher average age. Men in almost all age groups died more fre-

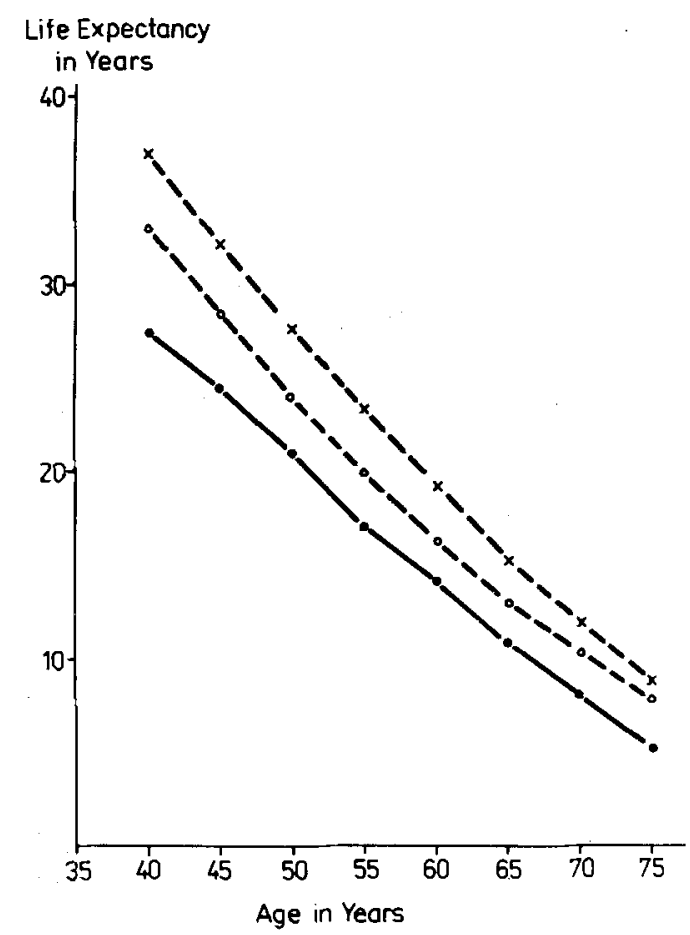

Fig. 4. Projected life-expectancy of diabetics newly detected in the Erfurt district during 1966 based on the mortality rate during the first year after diagnosis (current life table method) [20]. Due to the small number of patients, a separate analysis with regard to sex was not made. Control figures are based on official mortality figures for the general population in the German Democratic Republic in 1966/67 [23]. $\times-\ldots \times$ females and $O--O$ males in the general population; quently of ischaemic heart disease $(p<0.01)$, while cerebrovascular insufficiency and general arteriosclerosis caused more deaths in women (NS). Only three deaths were ascribed to diabetic nephropathy.

\section{Discussion}

Our patient population differs from those used in most other studies of prognosis in that selection factors have been eliminated, since it includes all diabetics newly discovered in a defined population during one calendar year. The age and sex characteristics of the patient group are typical of highly industrialised nations. Predictions made from these data with regard to prognosis are thus limited to non-insulin-dependent diabetes, since the number of newly manifested cases of insulin-dependent diabetes in one calendar year was too small for statistical analysis of prognosis.

The various methods applied to analyse this patient population indicate the lower life expectancy of non-insulin-dependent diabetes in comparison with persons of comparable age and sex within the total population. The fact that this excess mortality is already evident one year after diagnosis of diabetes is of fundamental importance.

The excess mortality in the diabetic group declined consistently with increasing age at detection. While the death rate of diabetics in the $40-49$ year group was about double that of the total population, there were no differences in persons aged over 75 years. Similar observations have been reported for hospitalised patients in Sweden [7], Oslo [14], and for approximately 5,000 patients of the Birmingham diabetic clinic [5]. The Joslin Clinic data also show the highest excess mortality in patients who died aged 25-34 years [11].

Table 3. Distribution of causes of death in 984 deceased diabetics (\%)

\begin{tabular}{|c|c|c|c|c|c|c|}
\hline Causes of death & Males & & Females & & Total & \\
\hline Coma & 2.5 & & 1.4 & & 1.8 & \\
\hline Macroangiopathy ${ }^{\mathrm{a}}$ & 60.0 & & 65.3 & & 63.4 & \\
\hline - Coronary heart disease & & 23.9 & & 17.0 & & 19.5 \\
\hline - Cerebrovascular disease & & 16.9 & & 22.6 & & 20.5 \\
\hline - Peripheral vascular disease & & 0.6 & & 0.6 & & 0.6 \\
\hline - General arteriosclerosis & & 18.6 & & 25.1 & & 22.8 \\
\hline Neopiasm & 14.1 & & 11.8 & & 12.6 & \\
\hline Infections & 9.3 & & 8.4 & & 8.7 & \\
\hline Accidents/suicide & 0.8 & & 2.4 & & 1.8 & \\
\hline Others & 13.3 & & 10.7 & & 11.7 & \\
\hline Total No. & 355 & & 629 & & 984 & \\
\hline
\end{tabular}

a Cardiovascular death includes all the cases who died of diseases $\mathrm{No}$. 400-448 of the WHO classification 
Because of differences in patient collection and methods, studies of prognosis are difficult to compare. In spite of different conditions, the degree of excess mortality for diabetics found in this study is similar to that reported by other workers $[5,7,10$, 24]. However, higher mortality rates have been reported in the Framingham study [1], in a group of diabetic life-insurance policy holders [4], in male diabetic employees of the Du Pont Company [25] and in hospitalised patients in Oslo [14].

Regarding relative differences in prognosis for the two sexes, conflicting results have been reported in the literature. A number of studies comparing diabetics with nondiabetics report a higher mortality ratio for diabetic women than for diabetic men $[1,5$, 26]. Others show no differences, or even a higher excess mortality rate in male diabetics $[6,9,10,12$, $14,24]$. In our study no significant sex differences in mortality ratios could be observed.

The excess mortality one year after diagnosis of diabetes might be explained by either of two factors. Hyperglycaemia may have been present for a considerable period before diagnosis, so that the actual duration of diabetes cannot be determined. A further cause of the early excess mortality might be that in non-insulin-dependent diabetics, arteriosclerosis frequently develops parallel with or even previous [27] to the diabetes. In this case it could be postulated that fewer diabetics die of consequent arteriosclerosis than a patients with arteriosclerosis and accompanying diabetes. The frequency of obesity and age distribution in our patients suggest that associated risk factors other than hyperglycaemia may have been important in promoting arterial disease. Because of the retrospective nature of the data, no discriminant analysis could be made. However, both hypertension and cardiovascular co-morbidity, but not overweight, seem to correlate with total mortality.

\section{References}

1. Garcia MJ, McNamara PM, Gordon T, Kannel WB (1974) Morbidity and mortality in diabetics in the Framingham population. Diabetes 23: 105-111

2. Keen H, Jarrett RJ, Alberti KGMM (1979) Diabetes mellitus: A new look at diagnostic criteria. Diabetologia 16: 283-285

3. Entmacher PS (1972) An insurance-clinical dialogue on diabetes. Trans Assoc Life Insur Med Dir Am 55: 205-217

4. Goodkin G (1975) Mortality factors in diabetes. A 20 years mortality study. J Occup Med 17: 716-721

5. Hayward RE, Lucena BC (1965) An investigation into the mortality of diabetes. J Inst Actuaries 91: 286-336

6. Bale GS, Entmacher PS (1977) Estimated life expectancy of diabetes. Diabetes 26: 434-438

7. Grönberg A, Larssen T, Jung J (1967) Diabetes in Sweden: A clinico-statistical epidemiological and genetic study of hospital patients and death certificates. Acta Med Scand 477 (Suppl): $1-275$
8. Constam GR (1977) Die Prognose des Diabetes. In: Oberdisse $\mathrm{K}$ (ed) Handbuch der inneren Medizin. 5th edn, vol 7: Stoffwechselkrankheiten, pt 2: Diabetes mellitus B. Springer, Berlin Heidelberg New York, pp 1067-1092

9. Deckert T, Poulsen JE, Larsen M (1978) Prognosis of diabetics with diabetes onset before the age of thirtyone. I. Survival, causes of death and complications. Diabetologia 14: 363-370

10. Królewski AS, Czyzyk A, Janeczko D, Kopczyński J (1977) Mortality from cardiovascular diseases among diabetics. Diabetologia 13: 345-350

11. Marks HH, Krall LP (1971) Onset, course, prognosis, and mortality in diabetes mellitus. In: Marble A, White P, Bradley RP, Krall LP (eds) Joslin's Diabetes Mellitus, 11 th edn. Lea \& Febiger, Philadelphia, pp 209-254

12. Palumbo FJ, Elveback LR, Chu CP, Connolly DC, Kurland LT (1976) Diabetes mellitus: Incidence, prevalence, survivorship, and causes of death in Rochester, Minnesota, 19451970. Diabetes 25: 566-573

13. West KM (1978) Epidemiology of diabetes and its vascular lesions. Elsevier, New York, pp 159-189

14. Westlund K (1969) Mortality of diabetics, report 13. Life Insur Comp Instit for Med Statistics at the Oslo City Hosp. PJ Schmidts Bogtrykkeri, Vojets

15. Panzram G (1973) Epidemiologie des Coma diabeticum. Schweiz Med Wochenschr 103: 203-208

16. Panzram G, Marx H, Frommhold E, Barthel R (1977) Untersuchungen über Sterbealter, erlebte Diabetesdauer und Todesursachen unter den Verstorbenen einer geschlossenen Diabetespopulation. Wien Klin Wochenschr 89: 147-150

17. Panzram G, Ruttmann B (1978) Prognose des Diabetes mellitus nach Frühdiagnose durch Glukosuriescreening. Ergebnisse einer 10jährigen Verlaufskontrolle. Schweiz Med Wochenschr 108: 221-225

18. World Health Organization (1965) Technical report series 310: 9-12

19. Cutler FJ, Ederer P (1958) Maximum utilization of the life table method in analysing survival. J Chron Dis $8 ; 699-712$

20. Shryock HS, Siegel JS and assoc (1976) The methods and materials of demography, condensed edn Stockwell EG. Academic Press, New York San Francisco London, pp 249-268

21. Sachs L (1973) Angewandte Statistik, 4th edn. Springer, Berlin Heidelberg New York. p 273 (21a), p 341 (21b)

22. Adam J, Scharf JH, Enke H (1977) Methoden der statistischen Analyse in Medizin und Biologie. VEB Verlag Volk und Gesundheit, Berlin, pp 99-277

23. Statistisches Jahrbuch der Deutschen Demokratischen Republik (1971) Staatsverlag der DDR, Berlin, pp 465-466

24. Dreyer K, Hey A (1954) Dodelighedsforhold blandt diabetikere. Ugeskr Laeger 116: 273-276

25. Pell S, D'Alonzo CA (1970) Factors associated with longterm survival of diabetes. J Am Med Assoc 214: 1833-1840

26. Kannel WB, McGee DL (1979) Diabetes and glucose tolerance as risk factors for cardiovascular disease: the Framingham study. Diabetes Care 2: 120-126

27. Tuba J (1968) Diabetes und Lipidstoffwechsel beim MyokardInfarkt in Abhängigkeit vom Alter. Med Hyg 26: 1311-1313

Received: 23 May 1980

and in revised form: 20 January 1981

Prof. Dr. sc. med. G. Panzram

Medizinische Poliklinik

der Medizinischen Akademie Erfurt

DDR-506 Erfurt

German Democratic Republic 